\title{
A combined rainfall infiltration model based on Green-Ampt and SCS-curve number
}

\author{
Jun Li, Zhonggen Wang* and Changming Liu \\ Key Laboratory of Water Cycle and Related Land Surface Processes, Institute of Geographic Sciences and Natural Resources Research, Chinese \\ Academy of Sciences, 100101 Beijing, China
}

\begin{abstract}
:
The Green-Ampt infiltration equation is an incomplete governing equation for rainfall infiltration due to the absence of an inertia term. The estimation of the capillary pressure head at the wetting front is difficult to determine. Thus, a major limitation of the Green-Ampt model is the constant, non-zero surface ponding depth. This paper proposes an integrated rainfall infiltration model based on the Green-Ampt model and the SCS-CN model. It achieves a complete governing equation for rainfall infiltration by momentum balance and the water budget based on the Green-Ampt assumption, and uses the curve number from the SCS-CN method to calculate the initial abstraction, which is used as a basic parameter for the governing equation of the intensity of rainfall loss during the runoff period. The integrated rainfall infiltration model resolves the dilemma for capillary pressure head estimation, overcomes the limitation of constant, non-zero surface ponding depth, and facilitates the calculation of runoff for individual flood simulations. Copyright (C) 2014 John Wiley \& Sons, Ltd.
\end{abstract}

KEY WORDS Green-Ampt; SCS-CN; runoff; infiltration; soil hydrology

Received 18 May 2014; Accepted 14 October 2014

\section{INTRODUCTION}

Calculation of runoff is an important process for individual flood simulations in hydrological investigations. One key problem is rainfall infiltration, which has led to a considerable amount of literature dealing with experimental observations, theoretical analyses, and empirical modelling. R. E. Horton first proposed this concept for storm hydrograph analysis and prediction (Horton, 1941). Since then several infiltration models have been developed, and they can be categorized into three groups: physically based, semi-empirical, and empirical models (Mishra et al., 1999).

The commonly used semi-empirical infiltration models in soil physics and hydrology are Kostiakov's model (Kostiakov, 1932), Horton's three-parameter model (Horton, 1941), and the SCS-CN (Soil Conservation Service Curve Number) model (USDA-SCS, 1971). Some models were developed for application in homogeneous porous media (e.g. Ghildal and Tripathi, 1987; Hillel, 1998; Jury et al. 1991) and others for

\footnotetext{
*Correspondence to: Wang Zhonggen, Professor, specialized in Hydrology and Water Resources, Key Laboratory of Water Cycle \& Related Land Surface Processes, Institute of Geographic Sciences and Natural Resources Research, Chinese Academy of Sciences, 100101 Beijing, China.

E-mail: wangzg@igsnrr.ac.cn
}

ponding conditions (e.g. Parlange et al., 1985; Salvucci and Entekhabi, 1994). Among the various infiltration models in the literature, the Green-Ampt model (Green and Ampt, 1911) is the first physically based equation describing the infiltration of water into the soil. It is widely used, such as in the Soil and Water Assessment Tool (SWAT) and Soil Water-Atmosphere-Plants (SWAP) (Gusev and Nasonova, 1998) land-surface models. However, the parameter $h_{f}$ (capillary pressure head at the wetting front) in the Green-Ampt model is difficult to estimate, and it has long been believed that this parameter had no obvious physical significance. Although Bouwer (1966) suggested that $h_{f}$ could be related to measurable soil characteristics, it still imposes difficulties to individual flood simulations.

The main objective of this paper is to provide an integrated rainfall infiltration model based on the GreenAmpt model and SCS-CN model. The Green-Ampt equation is an incomplete governing equation for rainfall infiltration due to the absence of an inertia term. We developed a complete governing equation for rainfall infiltration by momentum balance and the water budget based on the Green-Ampt assumption. The initial abstraction is used as a basic parameter for the governing equation of the intensity of rainfall loss during the runoff period. The initial abstraction was calculated using the SCS-CN method. 


\section{THEORY OF MODELS}

The physical content of Darcy's law

Steady water flow in a saturated vertical soil column (Figure 1 A) can be described using Darcy's law:

$$
\frac{Q}{A}=\bar{v}=K \frac{h_{s}+h}{h} .
$$

The soil permeability coefficient $(\mathrm{K})$ in Darcy's law is a measure of the rate of water flow through a saturated soil under a given hydraulic gradient in length unit over a given time unit. Under Darcy steady flow, the total pressure is balanced by the total viscous friction force:

$$
\rho g A \theta_{s} \times\left(h_{s}+h\right)=\rho g A \theta_{s} \times \frac{1}{K} \bar{v} h .
$$

The total viscous friction force can be described as:

$$
F_{v}=\rho g A \theta_{s} \times \frac{1}{K} \bar{v} h .
$$

Darcy's law can be derived from the Navier-Stokes equations via homogenization when neglecting the inertia term (Hubbert, 1956). Therefore, the soil permeability coefficient $(\mathrm{K})$ reflects the proportional relationship between the mass flow rate and the total viscous friction force.
$\mathbf{A}$

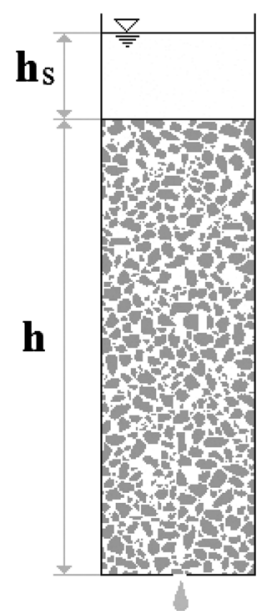

Darcy law
B Ponded Water

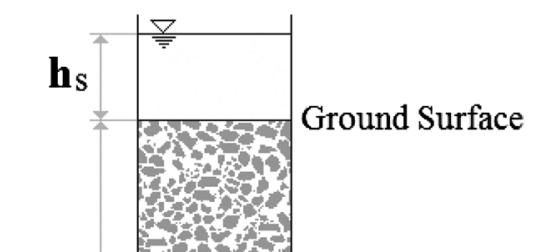
given by

$$
K \frac{h_{s}+h+h_{f}}{\theta_{s}-\theta_{0}}-\frac{d h}{d t} h=0 .
$$

The basic assumption behind the Green-Ampt equation is that water infiltrates into relatively dry soil as a sharp wetting front (Figure $1 \mathrm{~B}$ ). The Green-Ampt equation (Equation (4)) is an incomplete governing equation for rainfall infiltration due to the absence of an inertia term. The inertia term is more properly understood as shorthand for the principle of inertia as described by Newton in his First Law of Motion. In the absence of inertia, a momentum equation of motion is not strictly conserved. We derive a complete governing equation for rainfall infiltration by incorporating the momentum balance and water budget into the Green-Ampt model.

Based on the total viscous friction force (Equation (3)) and the momentum balance, the momentum equation for rainfall infiltration is given by

$$
\begin{aligned}
& \rho g A \theta_{s} \times\left(h+h_{s}+h_{f}\right)-\rho g A \theta_{s} \times \frac{1}{K} \bar{v} h \\
& =\frac{d\left(\rho A \theta_{s} \times h \bar{v}\right)}{d t} .
\end{aligned}
$$

The water budget equation for rainfall infiltration is

$$
\bar{v} \times d t=\left(\theta_{s}-\theta_{0}\right) \times d h .
$$

By substituting Equation (6) into Equation (5), we obtain

$$
\frac{K}{\theta_{s}-\theta_{0}}\left(h+h_{s}+h_{f}\right)-h \frac{d h}{d t}=\frac{K}{g} \frac{d}{d t}\left(\frac{d h}{d t} h\right) .
$$

To simplify equation Equation (7) we define

$$
\theta=\theta_{s}-\theta_{0}
$$

to obtain

$$
\frac{K}{\theta}\left(h+h_{s}+h_{f}\right)-h \frac{d h}{d t}=\frac{K}{g} \frac{d}{d t}\left(\frac{d h}{d t} h\right) .
$$

Equation (9) is the complete governing equation for rainfall infiltration based on the basic assumption of Green-Ampt model. The initial condition for Equation (9) is $\mathrm{h}=0$ at $\mathrm{t}=0$. 


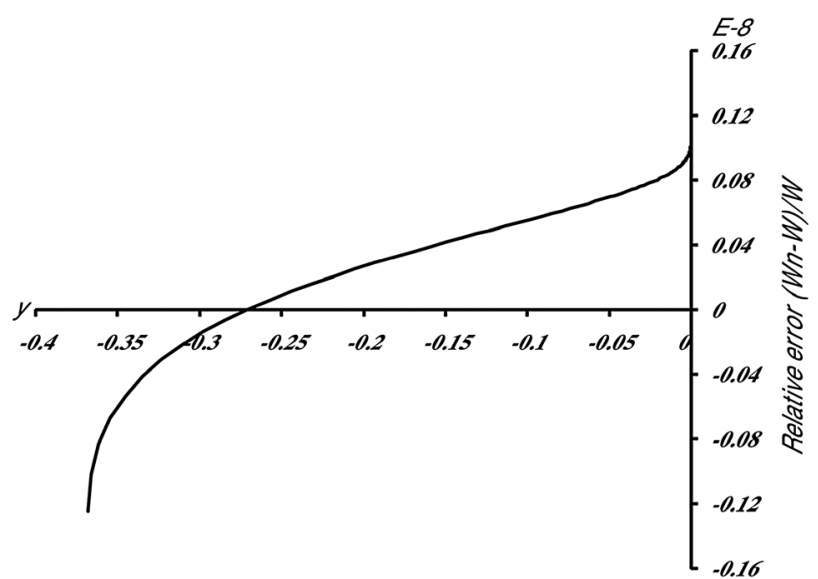

Figure 2. Relative error of the look-up table method for Lambert W function

Using Equation (6) we can compute the soil infiltration rate using

$$
f=\bar{v}=\left(\theta_{s}-\theta_{0}\right) \times \frac{d h}{d t}=\theta \times \frac{d h}{d t} .
$$

Runoff occurs when the rainfall intensity $(P)$ exceeds the soil infiltration rate $(f)$ at a point, $f=P$, namely:

$$
\frac{P}{\theta}=\frac{d h}{d t}
$$

By substituting Equation (11) into Equation (9), we obtain the design formula for the initial abstraction $z_{a}$, which is the cumulative infiltration at $f=P$ :

$$
z_{a}=\frac{K\left(h_{s}+h_{f}\right)-\frac{K P^{2}}{g \theta}}{P-K} .
$$

Using the initial abstraction as a basic parameter, we can rewrite the complete governing equation for rainfall infiltration Equation (9) into a new format. When $f \leq P$, we redefine the cumulative infiltration by:

$$
h(t)=z_{a}+z(t), \text { and } t=0 f=P
$$

Here, $z(t)$ is the intensity of rainfall loss during the runoff period. By substituting Equation (13) into Equation (9), we obtain

$$
\begin{aligned}
& \left(\frac{K P^{2}}{g \theta^{2}}+z_{a} \frac{P}{\theta}\right)+\frac{K}{\theta} z-\left(z_{a}+z\right) \frac{d\left(z_{a}+z\right)}{d t} \\
& =\frac{K}{g} \frac{d}{d t}\left(\frac{\theta\left(z_{a}+z\right)}{d t}\left(z_{a}+z\right)\right) .
\end{aligned}
$$

The inertia term is very small relative to the viscous and gravity terms for $f \leq P$. Neglecting the inertia term in Equation (14) gives

$$
\left(\frac{K P^{2}}{g \theta^{2}}+I_{a} \frac{P}{\theta}\right)+\frac{K}{\theta} z-\left(z_{a}+z\right) \frac{d z}{d t}=0
$$

To simplify equation Equation (15) we define the following parameters:

$$
A=\frac{K P^{2}}{g \theta^{2}}+z_{a} \frac{P}{\theta}, B=\frac{K}{\theta}, C=z_{a}
$$

Finally, Equation (15) can be rearranged to obtain:

$$
A+B z-(C+z) \frac{d z}{d t}=0 .
$$

Equation (17) is the governing equation for the intensity of rainfall loss during a runoff period.

\section{Calculation of initial abstraction using the SCS-CN model}

Assumptions of the Green-Ampt model are: (1) the water content profile is piston-type with a well-defined wetting front, (2) antecedent (i.e. prior to infiltration) water content distribution is uniform and constant, (3) water content drops abruptly to its antecedent value at the wetting front, (4) soil-water pressure head at wetting front is $\mathrm{h}_{\mathrm{f}},(5)$ soil-water pressure head at the surface, $h_{s}$, is equal to the depth of the ponding water, and (6) soil in the wetted region has constant properties. These assumptions lead to the following limitations of the GreenAmpt model: (1) lack of homogeneous soil conditions and properties, (2) constant, non-zero surface ponding depth, and (3) in most situations of rainfall or irrigation, the surface is not at constant water content (Ouyang et al., 1998). Also, estimating the value for $h_{f}$ is difficult as it has long been believed that $h_{f}$ has no obvious physical basis. Although Bouwer (1966) suggested that $h_{f}$ can be related to measurable

Table I. Typical mean values for soil hydraulic property parameters (Rawls et al., 1993; Ravi et al., 1998)

\begin{tabular}{llccc}
\hline & & \multicolumn{2}{c}{$\theta_{\mathrm{s}}$} & \multicolumn{2}{c}{$\mathrm{K}_{\mathrm{s}}$} & \\
\cline { 3 - 4 } & & $\mathrm{c}$ & \\
& Texture class & $\mathrm{cm}^{3} / \mathrm{cm}^{3}$ & $\mathrm{~m} / \mathrm{s}$ & \\
\hline 1 & Loamy sand & 0.401 & $1.70 \mathrm{E}-05$ & 50 \\
2 & Sandy loam & 0.412 & $7.19 \mathrm{E}-06$ & 55 \\
3 & Sandy clay loam & 0.330 & $1.19 \mathrm{E}-05$ & 60 \\
4 & Loam & 0.434 & $3.67 \mathrm{E}-06$ & 65 \\
5 & Silt loam & 0.486 & $1.89 \mathrm{E}-06$ & 70 \\
6 & Clay loam & 0.390 & $6.39 \mathrm{E}-07$ & 75 \\
7 & Silty clay loam & 0.432 & $4.17 \mathrm{E}-07$ & 80 \\
8 & Sandy clay loam & 0.321 & $3.33 \mathrm{E}-07$ & 85 \\
9 & Silty clay loam & 0.423 & $2.50 \mathrm{E}-07$ & 90 \\
10 & Clay & 0.385 & $1.67 \mathrm{E}-07$ & 95 \\
\hline & & & & \\
\hline
\end{tabular}

${ }^{a}$ Not mean values, but typical values used for testing the model in this paper. 


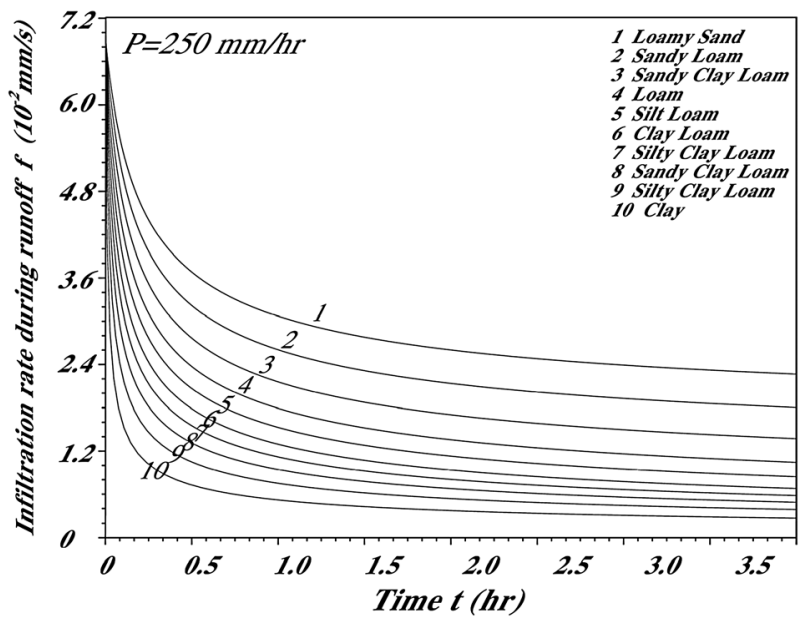

Figure 3. Series of curves for infiltration rate during runoff for different soil textures using the integrated rainfall infiltration model

soil characteristics, it is still very difficult to determine and assess whether an $\mathrm{h}_{\mathrm{f}}$ value is appropriate.

When the initial abstraction, $I_{a}$, is used as a basic parameter to solve Equation (15), estimation of this parameter becomes a key problem. However, this is easily addressed by the SCS-CN method. By using $I_{a}$, we resolve the dilemma of determining $\mathrm{h}_{\mathrm{f}}$ and overcome the limitations inherent within the Green-Ampt model (i.e. constant, nonzero surface ponding depth and the surface is not at a constant water content). The SCS method can only give an approximate value of the initial abstraction, which needs to calibrate by the actual hydrological sequence data.

The SCS runoff curve number (SCS-CN) method integrates the combined hydrologic effects of soil characteristics, land use, agricultural land management practices, and hydrologic and antecedent soil moisture conditions (McCuen, 1982). The original SCS-CN method was documented in Section 4 of the National Engineering Handbook in 1956 with several revisions through Mishra and Singh (2003). This method is based on a water balance equation and two hypotheses to compute surface runoff in small agricultural watersheds (Mishra and Singh, 1999, 2002, 2003, 2004a,2004b).

The SCS-CN assumes that $I_{a}$ is a function of the maximum potential retention $(\mathrm{S})$ :

$$
I_{a}=\lambda S
$$

$I_{a}$ is highly variable, but correlated with soil and land cover properties (Patil et al, 2008). In many studies for small agricultural watersheds, an empirical $I_{\mathrm{a}}=0.2 \mathrm{~S}$ expression is used (SCS, 1985). The $\mathrm{S}(\mathrm{mm})$ can be estimated as:

$$
S=25400 / C N-254
$$

where $C N$ is the soil moisture condition I curve number or hydrologic soil-cover complex number $(0 \leq C N \leq 100)$. $C N$ is related to the soil moisture condition II curve number, $C N_{I I}$, with the polynomial:

$$
\begin{aligned}
C N= & -16.91+1.348 C N_{I I}-0.01379\left(C N_{I I}\right)^{2} \\
& +0.0001177\left(C N_{I I}\right)^{3} .
\end{aligned}
$$

The $C N_{I I}$ is based on the antecedent moisture condition (AMC) II determined by the total rainfall in the 5-day period preceding a storm (USDA-SCS, 1971). Three levels of AMC are used: (1) lower limit of moisture content, (2) average moisture content, and (3) upper limit of moisture content.

Using $I_{\mathrm{a}}=0.2 S, \mathrm{z}_{\mathrm{a}}$ in Equation (9) can be calculated by:

$$
z_{a}=I_{a} /\left(\theta_{s}-\theta_{0}\right) .
$$

The actual retention, when the initial abstraction is not considered, is:

$$
F(t)=\left(\theta_{s}-\theta_{0}\right) z(t)
$$

When $f=P$ for $t=0$, the direct runoff $(Q)$ yields:

$$
Q(t)=P t-\left(\theta_{s}-\theta_{0}\right) z(t)
$$

Solutions for governing equations

Using Equation (6) we can obtain the soil infiltration rate:

$$
f=\theta \times \frac{d z}{d t}=\theta \times \frac{A+B z}{C+z} .
$$

The analytic solution of Equation (17) in an implicit form is

$$
t=\frac{z}{B}+\frac{B C-A}{B^{2}} \ln \left(1+\frac{B}{A} z\right) .
$$

The analytic solution of Equation (17) in an explicit form is

$z(t)=-\frac{A}{B}+\frac{B C-A}{B} W\left(\frac{A}{B C-A} \exp \left(\frac{A+B^{2} t}{B C-A}\right)\right)$

Here, $\mathrm{W}(\mathrm{x})$ is the Lambert $\mathrm{W}$ function which is defined by an inverse exponential function:

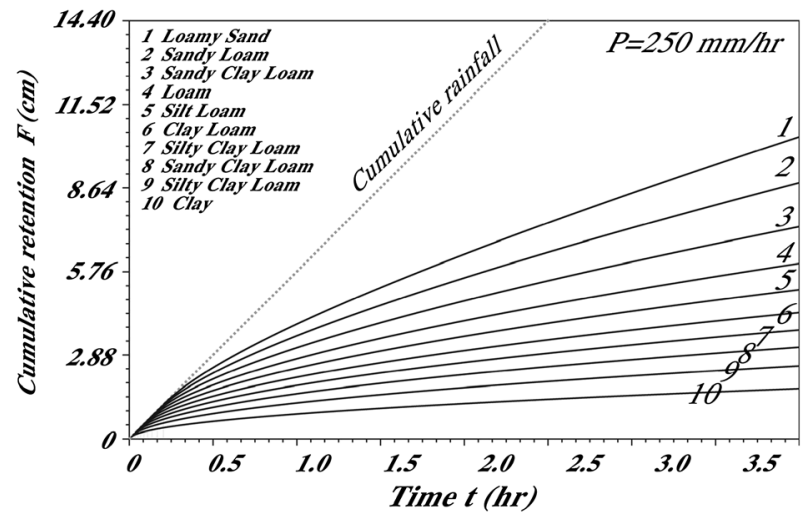

Figure 4. Series of curves for cumulative retention during runoff for different soil textures using the integrated rainfall infiltration model 


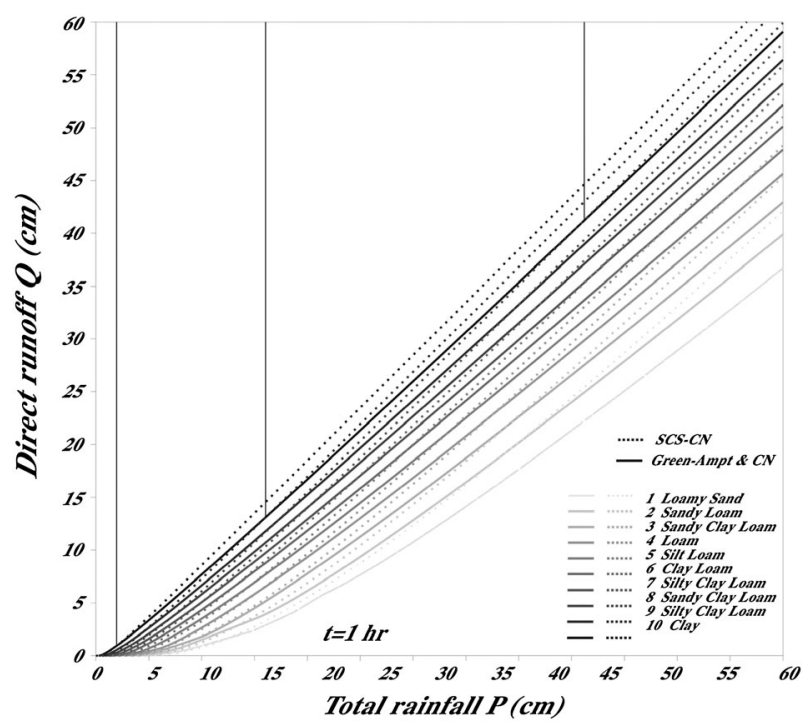

Figure 5. Comparison between the direct runoff simulations from the integrated rainfall infiltration model and SCS-CN model

$$
x=W(x) e^{W(x)} .
$$

When adopting Equation (26) it is important to calculate the numeric value of the Lambert $\mathrm{W}$ function. For the convenience of runoff calculations in hydrological simulation, we need an approximation for $\mathrm{W}(\mathrm{x})$ that covers the relevant range. Taking $\mathrm{P}=[1.001 \mathrm{~K}, \infty)$ and $\mathrm{t}=[0, \infty), \mathrm{x}$ can be estimated in the range $\left[0,-\mathrm{e}^{-1}\right)$. Taking $\mathrm{z}(\mathrm{t}) / \mathrm{z}_{\mathrm{a}}=[0.001, \infty), \mathrm{W}(\mathrm{x})$ is in the $(-\infty,-1)$ range. The Lambert $\mathrm{W}$ function has a branch-point at $\mathrm{x}=-\mathrm{e}^{-1}$, and in our case $\mathrm{W}(\mathrm{x})$ lies at the lower branch. Fritsch et al. (1973) proposed an efficient iteration scheme to more accurately compute $\mathrm{W}(\mathrm{x})$ based on an initial estimate:

$$
W_{n+1}=W_{n}\left(1+e_{n}\right)
$$

where $\mathrm{n}$ is the iteration count and $\mathrm{e}_{\mathrm{n}}$ is given by:

$$
e_{n}=\frac{z_{n}}{1+W_{n}} \frac{2\left(1+W_{n}\right)\left(1+W_{n}+\frac{2 z_{n}}{3}\right)-z_{n}}{2\left(1+W_{n}\right)\left(1+W_{n}+\frac{2 z_{n}}{3}\right)-2 z_{n}},
$$
and

$$
z_{n}=\ln \frac{x}{1+W_{n}}-W_{n} .
$$

A large number of approximation expressions for the Lambert W function in the Green-Ampt infiltration model have been proposed in the literature (e.g. Fritsch et al., 1973; Brutsaert, 1977; Salvucci and Entekhabi, 1994; Barry et al., 1995; Parlange et al., 2002). For the Green-Ampt model, the relevant range is $-31<\mathrm{W}(\mathrm{x})<-1$ and $-1.067168 \mathrm{E}-12<\mathrm{x}<-\mathrm{e}^{-1}$. Here, we use the look-up table method to obtain values. Using the numerical method, the step is 0.0001 , i.e.

$$
W_{n}=-1-0.0001 \times n \text {. }
$$

Using Equation (26), each $x_{n}$ is calculated for each $W_{n}$. A data table $\left(\mathrm{n}, \mathrm{x}_{\mathrm{n}}, \mathrm{W}_{\mathrm{n}}, \mathrm{x}_{\mathrm{n}+1}\right.$, and $\left.\mathrm{W}_{\mathrm{n}+1}\right)$ is stored which has 30000 data lines. In practice, for $x$, using the conditions $\left(x_{n}>x \geq x_{n+1}\right)$, we get only one data query result in the table, $\left(\mathrm{m}, \mathrm{x}_{\mathrm{m}}, \mathrm{W}_{\mathrm{m}}, \mathrm{x}_{\mathrm{m}+1}\right.$, and $\left.\mathrm{W}_{\mathrm{m}+1}\right)$, then the function $\mathrm{W}(\mathrm{x})$ is given by:

$$
W(x)=W_{m+1}-\frac{x_{m+1}-x}{x_{m+1}-x_{m}}\left(W_{m+1}-W_{m}\right) .
$$

Figure 2 shows that the maximum relative error is less than $1.0 \mathrm{E}-8$ for the relevant range of -1.067168 $\mathrm{E}-12<\mathrm{x}<-\mathrm{e}^{-1}$.

\section{Application of models}

The combined rainfall infiltration model based on Green-Ampt and the SCS-CN requires four parameters: $\theta_{\mathrm{s}}, \theta_{0}, \mathrm{~K}_{\mathrm{s}}$, and $\mathrm{CN}$. If no measurements are available, $\theta_{\mathrm{s}}$ and $\mathrm{K}_{\mathrm{s}}$ can be approximated based on soil texture (Table I). The $C N$ value can be obtained from published curve numbers tables (USDA-SCS, 1971).

The Green-Ampt and the SCS-CN models are two classical infiltration models; thus, there is no need to reprove their applicability. In order to demonstrate our combined rainfall infiltration model for different soil types, we set $\mathrm{P}=250 \mathrm{~mm} / \mathrm{h}$ and $\mathrm{t}=[0,4] \mathrm{h}$ to compute a series of infiltration curves (Figure 3 ) and curves of cumulative retention (Figure 4) during the runoff period, which cover their main ranges.

Although our combined rainfall infiltration model uses the $\mathrm{CN}$ (curve number) from the SCS-CN method to calculate the initial abstraction, there are fundamental differences between the two methods. The SCS-CN

\begin{tabular}{|c|c|c|c|c|}
\hline Code & Location & $\begin{array}{l}\text { Rainfall } \\
\text { frequency }\end{array}$ & $\begin{array}{c}\mathrm{R}^{2} \\
\text { combined } \\
\text { model }\end{array}$ & $\begin{array}{c}\text { Texture } \\
\text { class }\end{array}$ \\
\hline $\mathrm{C} 1$ & Qinghai Tianjun & 5 & 0.77 & Sandy clay \\
\hline $\mathrm{C} 2$ & Qinghai Nachitai & 5 & 0.99 & Sandy clay \\
\hline C3 & Qinghai Yanshiping & 6 & 0.86 & Sandy clay \\
\hline $\mathrm{C} 4$ & Xinjiang Baluntai & 11 & 0.86 & Sandy clay \\
\hline $\mathrm{C} 5$ & Xinjiang Dahegobi & 6 & 0.83 & Sand \\
\hline C6 & Qinghai Golmud & 5 & 0.97 & $\begin{array}{l}\text { Saline-alkali } \\
\text { soil }\end{array}$ \\
\hline $\mathrm{C} 7$ & Qinghai Tianjun & 6 & 0.47 & Sandy clay \\
\hline $\mathrm{C} 8$ & Xinjiang Dahegobi & 5 & 0.85 & Sand \\
\hline C9 & Xinjiang HejinGobi & 7 & 0.72 & Sandy clay \\
\hline $\mathrm{C} 10$ & Qinghai Yanshiping & 6 & 0.33 & Sandy clay \\
\hline $\mathrm{C} 11$ & Qinghai Kunlun Mountains & 5 & 0.85 & Silty sand \\
\hline \multirow{2}{*}{\multicolumn{2}{|c|}{ C12 Qinghai Tianjun }} & 8 & 0.95 & Loess \\
\hline & & Average & 0.79 & \\
\hline
\end{tabular}
method is a macroscopic and empirical infiltration model which uses a simple linear relationship between the reciprocal of total actual retention and the reciprocal of total rainfall during the runoff period as:

Table II. Modelling results of artificial rainfall experiments 

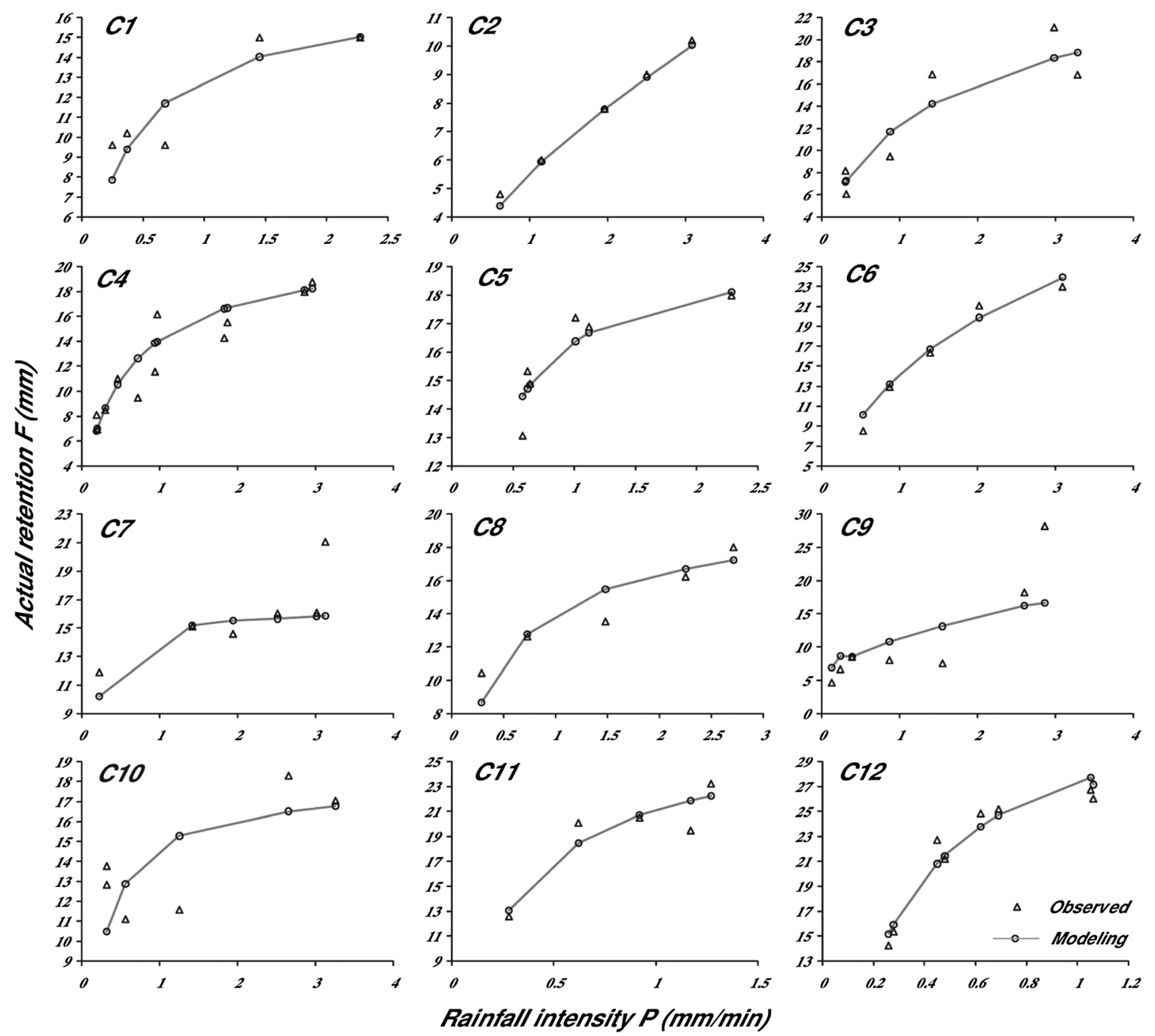

Figure 6. Artificial rainfall experiments and modelling by the combined rainfall infiltration model

$$
\frac{1}{F}=\frac{1}{S}+\frac{1}{P-I_{a}} .
$$

For rainfall infiltration processes, the cumulative infiltration is both the outcome variable and the driving force of gravity; thus, the Lambert W function is closest to the actual infiltration. Figure 5 shows that one runoff curve from the combined rainfall infiltration model crosses the runoff curves from the SCS-CN model at different time points. Overall, the SCS-CN method overestimates the direct runoff.

In order to predict the flood peak in ungauged watersheds, Liu (1978) carried out a series of artificial rainfall experiments in the fields for the period of 1958-1978 using different land surface and soil wetness conditions in many places in China. Six key types of data were recorded for each experiment, including rainfall intensity, initial abstraction duration, initial abstraction, runoff duration, actual retention during runoff period, and steady infiltration rate. We validate the combined rainfall infiltration model by this artificial rainfall experimental data. Table II and Figure 6 show that the combined rainfall infiltrations model a good accuracy. The chief reason of the errors is that the mean value of the steady infiltration rate is used as the saturated soil hydraulic conductivity for one experimental site, because no measurements are available.

\section{CONCLUSION}

We developed an integrated rainfall infiltration model based on the Green-Ampt model and the SCS-CN model. The Green-Ampt equation is an incomplete governing equation for rainfall infiltration due to the absence of an inertia term. We achieve the complete governing equation for rainfall infiltration by momentum balance and the water budget based on the Green-Ampt assumption. The estimation of capillary pressure head at the wetting front, $\mathrm{h}_{\mathrm{f}}$, is difficult to determine. We used the $\mathrm{CN}$ (curve number) from the SCS-CN method to calculate the initial abstraction. 
The initial abstraction is used as a basic parameter for the governing equation of the intensity of rainfall loss during the runoff period. This resolved the dilemma of determining the $h_{f}$ value and overcomes major limitations of the Green-Ampt model (i.e. constant, non-zero surface ponding depth and the surface is not at a constant water content). The integrated rainfall infiltration model, which only considers the rainfall infiltration during the runoff period, requires four parameters: $\theta_{\mathrm{s}}, \theta_{0}, K_{\mathrm{s}}$, and $\mathrm{CN}$. If no measurements are available, $\theta_{\mathrm{s}}$ and $\mathrm{K}_{\mathrm{s}}$ can be estimated using soil texture, while the $C N$ can be obtained from published values of SCS curve numbers. The integrated rainfall infiltration model significantly facilitates the calculation of runoff for individual flood simulation in hydrological investigations.

\section{ACKNOWLEDGEMENTS}

This research was funded by the National Natural Science Foundation of China, No. 41271048 and the key project of the National Natural Science Foundation of China, No. 41330529. Authors would also like to thank the editor and the anonymous reviewers for constructive comments to improve the paper.

\section{LATIN SYMBOLS}

\begin{tabular}{|c|c|c|}
\hline A & {$\left[\mathrm{m}^{2}\right]$} & cross-sectional area of soil column; \\
\hline$C N$ & {$[-]$} & soil moisture condition I curve number; \\
\hline$C N_{U}$ & {$[-]$} & soil moisture condition I curve number; \\
\hline $\mathrm{F}(\mathrm{t})$ & {$[\mathrm{m} / \mathrm{s}]$} & cumulative infiltration at the surface; \\
\hline $\mathrm{F}_{\mathrm{v}}$ & {$[\mathrm{N}]$} & total viscous friction force; \\
\hline$f(t)$ & {$[\mathrm{m} / \mathrm{s}]$} & infiltration rate in soil; \\
\hline $\mathrm{g}$ & {$\left[\mathrm{m} / \mathrm{s}^{2}\right]$} & acceleration of gravity; \\
\hline $\mathrm{h}_{\mathrm{f}}$ & {$[\mathrm{m}]$} & capillary pressure head at the wetting front; \\
\hline $\mathrm{h}_{\mathrm{s}}$ & {$[\mathrm{m}]$} & surface ponding depth; \\
\hline$h(t)$ & {$[\mathrm{m} / \mathrm{s}]$} & cumulative infiltration of soil water; \\
\hline$I_{a}$ & [m] & initial abstraction at the surface; \\
\hline$K_{s}$ & {$[\mathrm{~m} / \mathrm{s}]$} & soil saturated hydraulic conductivity; \\
\hline $\mathrm{P}$ & {$[\mathrm{m} / \mathrm{s}]$} & rainfall intensity; \\
\hline Q & {$\left[\mathrm{m}^{3} / \mathrm{s}\right]$} & direct runoff; \\
\hline$S$ & {$[\mathrm{~mm}]$} & potential maximum retention; \\
\hline $\mathrm{t}$ & {$[\mathrm{s}]$} & time; \\
\hline $\mathrm{W}(\mathrm{x})$ & {$[-]$} & Lambert $\mathrm{W}$ function; \\
\hline $\mathrm{z}_{\mathrm{a}}$ & [m] & initial abstraction depth in soil; \\
\hline$z(t)$ & {$[\mathrm{m} / \mathrm{s}]$} & cumulative infiltration depth in soil; \\
\hline$\rho$ & {$\left[\mathrm{kg} / \mathrm{m}^{3}\right]$} & density of water; \\
\hline$\lambda$ & {$[-]$} & coefficient; \\
\hline$\theta_{\mathrm{s}}$ & {$\left[\mathrm{cm}^{3} / \mathrm{cm}^{3}\right]$} & saturated volumetric water content; \\
\hline$\theta_{0}$ & {$\left[\mathrm{~cm}^{3} / \mathrm{cm}^{3}\right]$} & initial volumetric water content. \\
\hline
\end{tabular}

\section{REFERENCES}

Barry DA, Culligan-Hensley PJ, Barry SJ. 1995. Real values of the W-function. ACM Transactions on Mathematical Software (TOMS) 21(2): 161-171.

Bouwer H. 1966. Rapid field measurement of air entry value and hydraulic conductivity of soil as significant parameters in flow system analysis. Water Resources Research 2(4): 729-738.

Brutsaert W. 1977. Vertical infiltration in dry soil. Water Resources Research 13(2): 363-368.
Fritsch FN, Shafer RE, Crowley WP. 1973. Solution of the transcendental equation wew $=\mathrm{x}$. Communications of the ACM 16(2): 123-124.

Ghildal BP, Tripathi RP. 1987. Soil Physics. John Wiley \& Sons: New York. Green WH, Ampt GA. 1911. Studies on soil physics. Journal of Agricultural Science 4(1): 1-24.

Gusev YM, Nasonova ON. 1998. The land surface parameterization scheme SWAP: Description and partial validation. Global and Planetary Change 19(1): 63-86.

Hillel D. 1998. Environmental Soil Physics. Academic Press: New York (NY).

Horton RE. 1941. An approach toward a physical interpretation of infiltration-capacity. Soil Science Society of America Journal 5(C): 399-417.

Hubbert MK. 1956. Darcy's law and the field equations of the flow of underground fluids. Petroleum Transactions, AIME 207: 222-239.

Jury WA, Gardner WR, Gardner WH. 1991. Soil Physics. John Wiley and Sons, Inc.

Kostiakov AN. 1932. On the dynamics of the coefficient of waterpercolation in soils and on the necessity for studying it from a dynamic point of view for purposes of amelioration. Transactions of the 6th Commission of the International Society of Soil Science, Part A $\mathbf{6}$ : $17-21$.

Liu C. 1978. Calculation of rainstorm runoff in small watershed. Science Press, pp 22-25. (in Chinese)

McCuen RH. 1982. A Guide to Hydrologic Analysis using SCS Methods. Prentice-Hall, Inc.: Englewood Cliffs, New Jersey; pp 145.

Mishra SK, Kumar SR, Singh VP. 1999. Calibration of a general infiltration model. Hydrological Processes 13: 1691-1718.

Mishra SK, Singh VP. 1999. Another look at SCS-CN method. Journal of Hydrologic Engineering 4(3): 257-264.

Mishra S, Singh V. 2002. SCS-CN method. Part 1: Derivation of SCSCN-based models. Acta Geophysica Polonica 50(3): 457-477.

Mishra SK, Singh VP. 2003. Soil Conservation Service Curve Number (SCS-CN) Methodology. Kluwer Academic Publishers: Dordrecht, The Netherlands; pp 244-274.

Mishra SK, Singh VP. 2004a. Long-term hydrological simulation based on the Soil Conservation Service curve number. Hydrological Processes 18(7): 1291-1313.

Mishra SK, Singh VP. 2004b. Validity and extension of the SCS-CN method for computing infiltration and rainfall-excess rates. Hydrological Processes 18(17): 3323-3345.

Ouyang Y, Chen JS, Ravi V, Williams JR. 1998. Estimation of infiltration rate in vadose zone: Application of selected mathematical models. United States Environmental Protection Agency, Office of Research and Development. EPA/600/R-97/128b.

Parlange JY, Haverkamp R, Touma J. Infiltration under ponded conditions: 1. Optimal analytical solution and comparison with experimental observations. Soil Science 1985, 139(4): 305-311.

Parlange JY, Barry A, Haverkamp R. 2002. Explicit infiltration equations and the Lambert W-function. Advances in Water Resources 25: 8-12.

Patil JP, Sarangi A, Singh AK, Ahmad T. 2008. Evaluation of modified $\mathrm{CN}$ methods for watershed runoff estimation using a GIS-based interface. Biosystems Engineering 100(1): 137-146.

Ravi V, Williams JR, Burden DS. 1998. Estimation of infiltration rate in the vadose zone: Compilation of simple mathematical models. US Environmental Protection Agency, Office of Research and Development. EPA/600/R-97/128a.

Rawls WJ, Ahuja LR, Brakensiek DL, Shirmohammadi A. 1993. Infiltration and soil water movement. In Handbook of Hydrology, Maidment DR (ed). McGraw-Hill: New York; 5.1-5.51.

Salvucci GD, Entekhabi D. 1994. Explicit expressions for Green-Ampt (delta function diffusivity) infiltration rate and cumulative storage. Water Resources Research 30(9): 2661-2663.

SCS. 1971. Hydrology National Engineering Handbook, Section 4, Chapter 10. Soil Conservation Service. USDA: Washington DC.

SCS. 1985. Hydrology. National Engineering Handbook, Supplement A, Section 4 Chapter 4. Soil Conservation Service. USDA: Washington DC. 